with bevacizumab with an average age of 62 (ranging 45-79). 40 treatments were reviewed (one patient received two different bevacizumab regimens during the monitoring process), $42.5 \%$ of which followed the indications authorised by the EMA. The regimens that didn't fit to the technical data (57. $5 \%$ ) were as follows: $46 \%$ bevacizumab in monotherapy $15 \mathrm{mg} / \mathrm{kg} / 21$ days, $54 \%$ bevacizumab associated with other cytostatics different from paclitaxel or capecitabine. Combinations with bevacizumab not indicated in the technical data were: $37 \%$ bevacizumab $15 \mathrm{mg} / \mathrm{kg}+$ liposomal doxorubicin $75 \mathrm{mg} / \mathrm{m}^{2} / 21$ days, $37 \%$ bevacizumab $15 \mathrm{mg} / \mathrm{kg} /$ 21 days + vinorelbine $25 \mathrm{mg} / \mathrm{m}^{2}$ days 1 and $8,10 \%$ bevacizumab $15 \mathrm{mg} / \mathrm{kg} / 21$ days, $10 \%$ bevacizumab $10 \mathrm{mg} / \mathrm{kg}$ +irinotecan to $125 \mathrm{mg} / \mathrm{m}^{2} / 15$ days and $6 \%$ bevacizumab $15 \mathrm{mg} / \mathrm{kg}+$ docetaxel $100 \mathrm{mg} / \mathrm{m}^{2} / 21$ days.

Conclusions Despite the extension of the bevacizumab indications in 2011 by the European Medicines Agency (EMA) the offlabel use of bevacizumab remains high, probably due to the clinical evidence with bevacizumab, which has evolved rapidly in recent years. In this sense, the importance of pharmacists' role should be stressed in evaluating the use of medicine in relation to the recent evidence of the $\mathrm{MBC}$.

No conflict of interest.

\section{GRP-178 SURFACE CONTAMINATION WITH ANTINEOPLASTIC DRUGS IN SEVEN FRENCH HOSPITAL PHARMACIES}

\section{doi:10.1136/ejhpharm-2013-000276.178}

'LMM Lê, ${ }^{2} \mathrm{D}$ Pradeau, 'P Prognon, 'E Caudron. 'Hopital Européen Georges Pompidou, Pharmacy, Paris, France; ${ }^{2}$ Pharmaceutical Establishment of Paris Hospitals, Analytical Development Laboratory, Paris, France

Background Due to their carcinogenic, mutagenic and teratogenic properties, handling cytotoxic drugs presents a risk of occupational exposure for healthcare workers.

Purpose To evaluate and limit occupational risk, environmental monitoring was conducted in 7 French hospital pharmacies that prepare formulations of carboplatin, cisplatin and oxaliplatin. Platinum was used as the tracer ( $20 \%$ of the production).

Materials and Methods From 2010 to 2012, 7 cytotoxic drug preparation units were investigated. Different types of surface were evaluated: the external surface of vials containing cytotoxic materials, workplace surfaces and the surfaces of antineoplastic drug preparations. Surfaces were sampled with a moistened swab. After pre-concentration by cloud point extraction, the quantity of elemental platinum was evaluated by graphite furnace atomic absorption spectrometry. The lower limit of detection corresponded to 2 ng of platinum per sample.

Results A total of 518 samples analysed had various levels of contamination and we found a frequency of cytotoxic contamination of more than $37 \%$ of samples (>2 ng). Contamination was found on $38 \%$ of vials of cisplatin, carboplatin and oxaliplatin from different manufacturers ( $\mathrm{n}=111$, max $66 \mathrm{ng}$ ), $56 \%$ of cytotoxic preparations ( $\mathrm{n}=18$, max $78 \mathrm{ng}$ ) with $29 \%$ of packagings ( $\mathrm{n}=24$, max $15 \mathrm{ng})$ and $56 \%$ of workplace surfaces $(\mathrm{n}=365)$ contaminated. Surfaces inside isolators were the most contaminated area $(59 \%$, $\mathrm{n}=169)$ compared with storage areas $(28 \%, \mathrm{n}=89)$, controlled areas $(15 \%, n=55)$, control laboratories $(24 \%, n=25)$ and other areas $(4 \%, n=27)$. However the highest level of contamination was found inside storage boxes of vials containing cytotoxics with more than 20,000 ng of Pt.

Conclusions Regarding environmental monitoring, two major sources of contamination were identified: the outer surface of vials of cytotoxic material and handling cytotoxic drugs inside the isolator. Other contamination spreads from those initial points of contamination. Thus, it seems necessary to use effective individual protective equipment but also to use efficient cleaning protocols to limit chemical contamination and thus, to prevent occupational exposure.

No conflict of interest.

\section{GRP-179 SWITCH FROM CERA TO EPO ZETA IN PATIENTS WITH ANAEMIA AND CHRONIC KIDNEY DISEASE}

doi:10.1136/ejhpharm-2013-000276.179

'L Perani, 'C Scolari, ${ }^{1} \mathrm{~A}$ Braus, ${ }^{2} \mathrm{E}$ Galli. ${ }^{1} \mathrm{General}$ Hospital of Treviglio Caravaggio, Pharmacy Unit, Treviglio (BG), Italy; ${ }^{2}$ General Hospital of Treviglio Caravaggio, Nephrology Department, Treviglio (BG), Italy

Background As the result of a possible shortage of methoxy polyethylene glycol epoetin beta (CERA) within Italy, with the agreement of the EMA, AIFA (the Italian Medicines Agency) prepared a document inviting prescribers to switch patients who were undergoing treatment with different doses of CERA to any Erythropoiesis Stimulating Agent (ESA), for the treatment of anaemia associated with chronic kidney disease (CKD).

This recommendation emphasised the need to monitor haemoglobin levels $(\mathrm{Hb})$ and safety and efficacy parameters.

Purpose To evaluate variations of efficacy ( $\mathrm{Hb}$ levels) and safety (immunological reaction) of a new treatment, in patients with CKD after switching from CERA to epoetin zeta (EPO zeta), as per international and national guidelines.

To keep the same $\mathrm{Hb}$ level obtained before the shift.

To compare the cost differences of the two ESAs.

Materials and Methods A preliminary observational study (April-September 2012) was carried on CKD patients in haemodialysis care at the Department of Nephrology. The patients enrolled were treated with some of the doses of CERA indicated in the Recommendation for at least ten months. We evaluated ESA dosage, $\mathrm{Hb}$ level and dosage $/ \mathrm{kg}$.

Results The study included 12 patients ( 7 men and 5 women) with mean age 56.64 years (range 40-75). All patients were treated with EPO zeta (average initial dose $6500 \mathrm{IU} / \mathrm{Kg} /$ week); after monthly monitoring of $\mathrm{Hb}$ levels, the initial dose of EPO zeta was increased by $7.69 \%$ (average dose $7000 \mathrm{IU} / \mathrm{Kg} /$ week) and three months later, the median $\mathrm{Hb}$ level observed was $11.28 \mathrm{~g} / \mathrm{dl}$.

Statistical analysis showed no significant difference between CERA and EPO zeta in terms of Hb level ( $\mathrm{P}=0.408)$.

No adverse events due to treatment were recorded; no variation in iron supplementation

The use of EPO zeta resulted in savings of 250 euro per month/ patient versus CERA treatment.

Conclusions After switching from CERA therapy, the use of EPO zeta appears effective and safe for CKD patient treatment. Data showed the need to increase the dose of EPO zeta to maintain a steady $\mathrm{Hb}$ level. Despite the increased consumption, the use of this biosimilar could contribute to containing pharmaceutical costs.

No conflict of interest.

\section{GRP-180 TELAPREVIR AND BOCEPREVIR: SAFETY AND EFFICACY OF THE INITIAL TREATMENTS IN THE HOSPITAL}

doi:10.1136/ejhpharm-2013-000276.180

A Valle Díaz de la Guardia, C García Fernández, C Gómez Peña, J Cabeza Barrera. Hospital Universitario San Cecilio, Farmacia Hospitalaria, Granada, Spain

Background These novel treatments for hepatitis $C$ have been recently approved in Spain. Several studies have confirmed their great efficiency in achieving good virological response.

Purpose To present the preliminary results of treatment with these drugs in a 600-bed hospital and find the adherence of patients to triple treatment: ribavirin, peginterferon and boceprevir or telaprevir. 
Materials and Methods All patients treated with telaprevir or boceprevir since its inclusion in the hospital (January 2012) were included. We studied the medical records to see if patients were treatment-naive or a previously treated, and we checked the occurrence of adverse reactions associated with antiviral treatment. To calculate the adherence, dispensing records from the Pharmacy Service were used and percentage adherence was calculated. The primary end point was the rate of rapid virological response at week 4 for patients who completed one month of treatment and at week 12 for patients who completed three months. We used a formula for calculating percentage adherence, stating that a patient was adherent if treatment intake exceeded $95 \%$.

Results At the time of the study (June 2012), 8 patients were treated with telaprevir ('T group') and 6 with boceprevir ('B group'). In the $\mathrm{T}$ group there were 2 treatment-naive patients and 6 with no response to previous treatment. All patients who completed three months of treatment (4 patients) achieved rapid virological response. The other 4 patients completed one month of treatment and in all of them HCV RNA was undetectable at week 4. Pruritus and eczema were the most common adverse reactions in group $\mathrm{T}$ (in $90 \%$ of patients). In the B group, there were 3 treatment-naive patients and 3 previously treated. Four patients completed three months of triple treatment, but one of them did not reach rapid virological response. Regarding the 2 patients who completed one month of treatment, only one patient had undetectable HCV RNA at week 4 . There were no adverse reactions related to boceprevir in this group. Patients of both groups were adherent to treatment.

Conclusions The addition of boceprevir or telaprevir to standard treatment increased the rates of rapid virological response, in treatment-naive and previously treated patients. The role of the Pharmacy Service is very important in promoting patient adherence despite the adverse effects that may occur.

No conflict of interest.

\section{GRP-181 THE CLINICAL IMPACT OF CALCIUM-CEFTRIAXONE INTERACTION IN PATIENTS ON TOTAL PARENTERAL NUTRITION}

doi:10.1136/ejhpharm-2013-000276.181

J Diaz-Navarro, MA Blanco-Castaño, JF Lopez-Vallejo, R Castaño-Lara, S FénixCaballero, E Ríos-Sánchez, JM Borrero-Rubio, E Alegre-Delrey, MJ GándaraLadrondeguevara, C Palomo-Palomo. Hospital Universitario Puerto Real, Hospital Pharmacy, Puerto Real (Cádiz), Spain

Background A safety alert about the possibility of a potentially fatal interaction in patients, especially neonates, has been issued by the FDA. Patients treated with ceftriaxone and concomitant total parenteral nutrition (TPN) are at potential risk of pulmonary or intravascular precipitation of a ceftriaxone-calcium complex.

Purpose To assess patients with TPN at potential risk of suffering a calcium-ceftriaxone interaction, its clinical significance in our hospital, and to develop a software tool for real-time detection.

Materials and Methods Patient treatment (including ceftriaxone $1 \mathrm{~g}$ IV/IM and $2 \mathrm{~g}$ IV) from March 2010 to May 2011 was obtained using the Farmatools application of the Computerized-PhysicianOrder-Entry-System. TPN patient requirements, including neonates, were obtained from a database we had designed ourselves. Patients who required calcium-supplemented TPN and concomitant administration of ceftriaxone were selected. Finally, administration complications or symptoms of intravascular or pulmonary precipitation were checked on patient Medical-Digital Health Records (Diraya).

To detect real-time ceftriaxone-calcium interactions when TPN is being prescribed, the Farmatools medicines database and the pharmacist TPN application were associated using ODBC(Open DataBase Connectivity).
Results During the period studied, 15495 patients were hospitalised, 1044 received ceftriaxone, and 838 administrations of TPN were prepared for 85 patients. A total of 16 patients (18.8\%), none of them neonates, were found to have received TPN and ceftriaxone at the same time: 10 staggered administrations, and 6 (7\%) concomitantly; the patients were exposed to the described interaction. None of the 6 patients showed clinical complications arising from such an interaction.

As a result of this study, the TPN prescribing and validation programme in the pharmacy was updated. When calcium is prescribed in a TPN, the application automatically searches for ceftriaxone in the patient's medicines and notifies the pharmacist in real time.

Conclusions Less than $10 \%$ of TPN patients could have suffered a ceftriaxone-calcium interaction in our hospital.

1. No neonates were exposed to this risk

2. None of the patients had clinical complications due to this interaction

3. The pharmacist TPN application was updated for real-time detection.

No conflict of interest.

\section{GRP-182 THE CLINICAL PHARMACIST'S IMPACT ON THE APPROPRIATE USE OF MEDICINES IN ELDERLY PATIENTS}

doi:10.1136/ejhpharm-2013-000276.182

'F Arnaud, ' $\mathrm{F}$ Dubois, ${ }^{2}$ Soulairol, ' $\mathrm{M}$ Knight, ${ }^{1} \mathrm{C}$ Roux, ${ }^{1} \mathrm{JM}$ Kinowski. ' $\mathrm{CHU}$ Carémeau, Pharmacy, Nimes cedex 9, France; ${ }^{2}$ AFSSAPS, Hospital preparations, Paris, France

Background Adverse effects caused by the treatment are frequent in the elderly and most often result from an inappropriate prescription. Experts have published a list of potentially inappropriate medicines for the elderly (aged 75 and over) [1].

Purpose To measure the clinical pharmacist's impact on compliance with this reference work.

Materials and Methods Our study was carried out in two units, the infectious and tropical diseases unit (SMIT) and a multipurpose medicine unit (MEPO) over a 1.5 -month period. Drug prescriptions for patients aged 75 and over were analysed in the units after medicines reconciliation by the clinical pharmacist. Conformity with the list of potentially inappropriate medicines (MPIs) was assessed on the optimised medical record (BMO) and the hospital prescription entry. The list of MPIs was divided into three categories of treatment: unfavourable risk/benefit ratio (type 1), questionable effectiveness (type 2) and unfavourable risk/benefit ratio and questionable effectiveness (type 3). When an inappropriate medicine was prescribed, the clinical pharmacist suggested interruption or alternative treatments.

Results Medicines reconciliation was conducted on 32 patients aged 75 and over in the two units (9 in SMIT and 23 in MEPO). Prescription of MPIs were identified for 11 patients (7 in MEPO and 4 in SMIT). The distribution of these MPIs was: $54.5 \%$ for type 1 , $18.3 \%$ for type 2 and $27.2 \%$ for type 3 . Medicines were stopped (54.5\%), switched $(18.2 \%)$ or continued $(27.3 \%)$.

Conclusions We found more at-risk patients in MEPO than in the SMIT. In $27.3 \%$ of cases, treatments were continued after consulting the doctor and reassessing the risk/benefit ratio and effectiveness. In $72.7 \%$ of cases the clinical pharmacist's contribution led to stopping or switching the MPI, confirming his essential role in the compliance with standards.

Reference

1. M.-L. Laroche, F. Bouthier, L. Merle, J.-P. Charmes. La Revue de Médecine Interne, Volume 30, Issue 7, July 2009, pp. 592-601.

No conflict of interest. 